Authors. (2017). "Choosing by advantages; benefits analysis and implementation in a case study, Colombia." In: Proc. $26^{\text {th }}$ Annual Conference of the International. Group for Lean Construction (IGLC), González, V.A. (ed.), Chennai, India, pp. 636-646. DOI: doi.org/10.24928/2018/0531. Available at: www.iglc.net.

\title{
CHOOSING BY ADVANTAGES; BENEFITS ANALYSIS AND IMPLEMENTATION IN A CASE STUDY, COLOMBIA
}

\author{
Juan Pablo Romero Cortes ${ }^{1}$, Jose Luis Ponz-Tienda ${ }^{2}$, Jose Miguel Delgado ${ }^{3}$ and \\ Laura Gutierrez-Bucheli ${ }^{4}$
}

\begin{abstract}
There are many methods of multicriteria decision analysis (MCDA), each one with properties and benefits. In the Architecture, Engineering, and Construction (AEC) sector most of the time, the decision-making involve different interest of the stakeholders of the projects, must of the times applying methods with the focus on the result. This paper presents a case study of a new University's facility construction that compares the traditional decision-making approach used in the design-bid-build procurement method of AEC industry in Colombia with an MCDA approach. Choosing By Advantages (CBA) has been used to analyse the reasons that could help explain why the subcontractor of a project construction was not meeting the client's expectations during project execution. Results include a discussion of main differences between these decision methods, the main difference is that in traditional decision-making approach the main criterion was cost while in the CBA was value. Consequently, the method's results were different for the alternatives.
\end{abstract}

\section{KEYWORDS}

Choosing By Advantages (CBA), multicriteria decision analysis, contractor selection.

\section{INTRODUCTION}

Decision-making may be one of the most common processes that faces professionals in the day-to-day work, but this practice could be very complex, especially when several objectives, factors, criteria and alternatives must be considered. Nowadays there are

1 Project manager, Dep. of Civil and Environmental Engineering. Universidad de Los Andes, Bogotá, Colombia, (57-1) 3324312,jp.romero985@uniandes.edu.co

2 Assistant Professor, Dep. of Civil and Environmental Engineering. Director of Construction Engineering and Management, Universidad de Los Andes, Bogotá, Colombia, (57-1) 3324312, jl.ponz@uniandes.edu.co

3 MSc Student, Dep. of Civil and Environmental Engineering. Universidad de Los Andes, Bogotá, Colombia, (57-1) 3324312, jm.delgado1298@uniandes.edu.co

4 Instructor Professor, Dep. of Civil and Environmental Engineering., Universidad de Los Andes, Bogotá, Colombia, (57-1) 3324312, la.gutierrez725@uniandes.edu.co 
many decision-making methods aimed to obtain the best results for the decision-making process, but its application used to be complex with questionable or mixed results at best.

In the Architecture, Engineering, and Construction (AEC) sector, the decisions taken are of great importance in order to increase the value in the different stages of the projects. One of the most critical decisions is the selection of the contractors, which implies not only the cost of the different alternatives but also technical and quality factors among others. Due to the importance of this process, this research analyses and compare the traditional methods used actually in the Colombian Industry with the Choosing By Advantages (CBA) method in the selection process of the structural contractor in a new University's facility construction.

In order to expose this proposal properly, this research is organized as follows. First, a literature review of the state-of-knowledge of the decision-making in the AEC is shown and consequently the next section details the traditional method selection used in the design-bid-build procurement method in Colombia. Next, a real academic construction project is used as an example of application, exposing and comparing the results obtained by the traditional and CBA method. Finally, on the basis of the results obtained, the conclusions, limitations and further research are drawn.

\section{STATE OF THE ART}

The multidisciplinary nature of decision-making in the AEC sector and the involvement of multiple stakeholders, such as designers and users, often result in decision tasks with multiple objectives (Kpamma, Adinyira, Ayarkwa, \& Adjei-Kumi, 2016). An example of this is the construction project outcome that may be measured in terms of time, cost and quality achieved (Holt, Olomolaiye, \& Harris, 1995). Commonly, the time-cost trade-off problem is a known as bi-objective problem in the field of project management where quality has been considered as an objective which is improved by increasing the cost of the project (Fallah-Mehdipour, Bozorg Haddad, Rezapour Tabari, \& Mariño, 2012).

In the example above, there is a conflict management situation where the decision involves multiple objectives. How is shown in the Figure 1, the nature of these decision tasks calls for approaches known as multicriteria decision-analysis (MCDA) (Abraham, Lepech, \& Haymaker, 2013). The MCDA may be considered as a complex and dynamic process (Kumar et al., 2017) including two levels: one managerial and one engineering level. The managerial level defines the objectives and chooses the best alternative and in the other hand, the engineering level defines the different alternatives and points out the consequences of choosing any one of them from the standpoint of various criteria, in this order of ideas; this level also performs the multicriteria ranking of alternatives (Opricovic \& Tzeng, 2004).

Furthermore, there are many methods of MCDA, its use depends on the functions defined in the problem (Kumar et al., 2017). The CBA decision system developed by Jim Suhr (1999) is one of the methods that takes into account the comparisons of the advantages of alternatives (Kpamma et al., 2016) in order to construct the preferences of the decision-makers (Arroyo, Tommelein, \& Ballard, 2012). Consequently, CBA 
Juan Pablo Romero Cortes, Jose Luis Ponz-Tienda, Jose Miguel Delgado

and Laura Gutierrez-Bucheli

promotes the correct use of information (Karakhan, Gambatese, \& Rajendran, 2016) basing decisions in objective questions, relevant facts, more consistent and less subjective processes (Suhr, 1999).

In the literature review, CBA is not well known (Schöttle \& Arroyo, 2017) but increasingly it has become a valuable method because consider different factors, which affect the alternatives as social and environmental factors that are not traditionally considered (Arroyo, Tommelein, \& Ballard, 2016). In contrast with other methods, CBA considers cost separately from other factors and does not treat it as a criterion (Parrish \& Tommelein, 2009), in other words, in CBA, the cost in considered as a restriction and not as a factor.

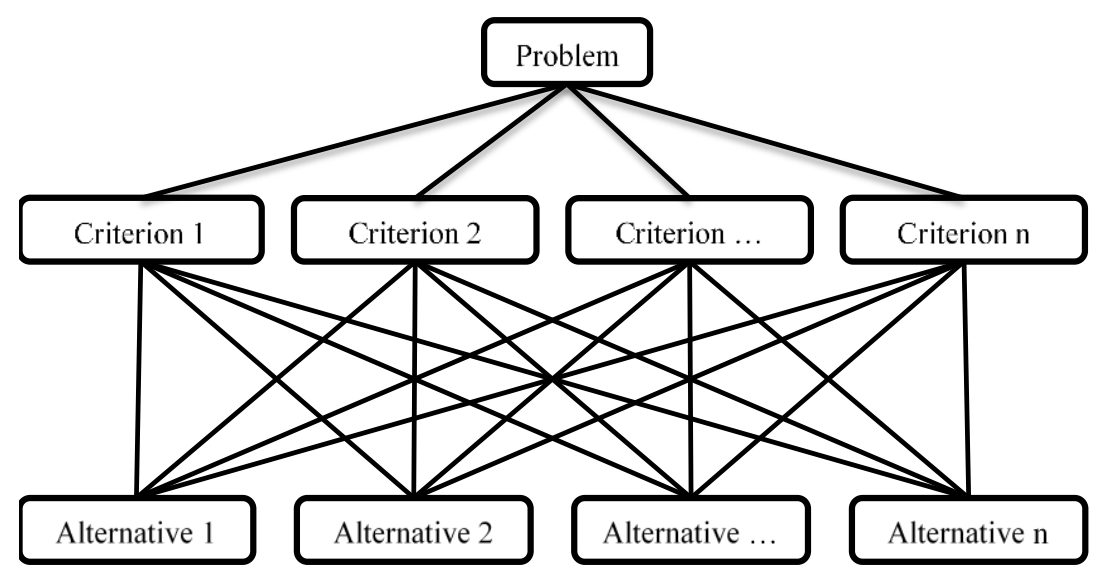

Figure 1: Multicriteria decision analysis diagram (Vallejo-Borda, Gutierrez-Bucheli, Pellicer, \& Ponz-Tienda, 2015)

The general phases of CBA implementation have evolved thanks to innovation phases. Paz Arroyo et al. (2013) describe that CBA Tabular method, for moderately complex decision, consist of seven steps: (1) identify alternatives, (2) define factor, (3) define must/want have criteria for each factor, (4) summarize the attributes of each alternative, (5) decide the advantages, (6) decide the importance of each advantage and (7) evaluate money data. In addition, the terminology used by CBA for the decision-making process must be understood before making any application (Martinez, Tommelein, \& Alvear, 2016):

- Alternative: Person, thing or plan which is a subject of choice.

- Factor: An element, part, or component of a decision.

- Criterion: A decision rule, or a guidance - usually, either a must or want.

- Attribute: A characteristic, quality, or consequence of one alternative.

- Advantage: A benefit, gain, improvement, or betterment.

The use of CBA in the AEC industry has been framed, in its majority, in the design and construction decision making (Parrish \& Tommelein, 2009) for example to select the formwork system (Martinez et al., 2016), the ceiling tile (Arroyo et al., 2013), the fall protection measures (Karakhan et al., 2016), the sustainable materials (Arroyo et al., 
2016), among others. In the case of contractor selection, the MCDA is suggested to be a viable method (Cheng \& $\mathrm{Li}, 2004$ ) and especially for contractor selection, it has been used methods like weighting-rating-calculating (WRC), best value selection (BVS), and CBA (Schöttle \& Arroyo, 2017). Despite that, in Colombia Lean Construction has being explain in three main pillars: culture, philosophy and technology with various methodologies (Pellicer \& Ponz-Tienda, 2014), even so, the use of new tools is difficult and face similar barriers related to contractors' engagement, reluctance to change and lack of training (Mejía-Plata et al., 2016). However, the research is limited about the differences based on a comparison of CBA and traditional industry methods of contractor selection, which have a similar nature to the value-based decision-making methods (usually confused with cost) that is based on the factors to be evaluated.

\section{TRADITIONAL METHOD OF CONTRACTOR SELECTION}

The contractor selection processes in the construction industry could be the most complex procedures in terms of the data analysis, due to the amount and nature of the data required for the decision problem. In order to provide transparency to these processes, guidelines and general rules were established to carry out the selection and hiring processes in Colombia through the law 80 of 1993. This document, updated with the law 1150 of 2007, institute the principles to ensure the objectivity in the selection. In this sense, the choice is made to the offer more favorable and following the purposes of the contractor, without taking into consideration the factors of any kind of subjective motivation like affection or interest.

It also establishes that the selection and qualification factors, which are established in the contract specifications, have to include criteria such as legal capacity, experience conditions, financial and organizational capacity of the proponents. In the same way, the requirement of such factors must be adequate and proportional to the nature of the contract to be subscribed and its value. Finally, it is established that the most favourable offer will be the most advantageous for the contractor, taking into account the technical and economic factors contained in the specifications.

In the case of entities of a private nature, the law 80 does not act as a binding regulation, but as a guide or principles with the aim of generating transparency in the decision processes. This is reflected in the fact that, despite not being obliged to do so, most private organizations structure their search and selection processes for contractors as established in Law 80. In these processes, the documentation that allows to evaluate the factors that are requested and described in the legislation, in addition to the methods of weighting or scoring of the proposals, both in technical and economic aspects, which, by assigning a percentage to the factors, are adapted to take into account value the compliance for each proponent.

\section{RESEARCH METHOD}

The focus of this study is the comparison of the CBA with the traditional method in the Colombian AEC Industry. With the goal of establishing if the CBA method provides 
Juan Pablo Romero Cortes, Jose Luis Ponz-Tienda, Jose Miguel Delgado

and Laura Gutierrez-Bucheli

significant advantages and add value over the other method, first, a background literature study of MCDA was made in order to deepen about the CBA application and its relation with similar methods used for contractor selection. In addition, from the case study, it was possible to compare the results of CBA using the process proposed by Paz Arroyo et al. (2013) with the results obtained based on the selection and hiring processes through the law 80 of 1993 of Colombia. Finally, the paper analyses the impacts of the decision taken on the project develop.

\section{CASE STUDY}

The selected project is an University's facility construction conformed by $8,555 \mathrm{~m} 2$ constructed in irregular five stories and three basement building located in the middle of the campus of the Universidad de Los Andes (see Figure 2), located along the slope of the eastern range of the Andes Mountains.

The main procurement method adopted at Universidad de Los Andes is Design-BidBuild (DBB). Moreover, this building was not the exception. When the project is in the construction-building process, most construction systems are already assigned to a contractor and a few ones are now in the final phase of the bidding process. In order to support these decisions, the project manager provided all the project information needed for the process: a) the contract specifications where specify the factors and the criterions, b) the four alternatives proposals and c) the tendering evaluation used to take the decision.

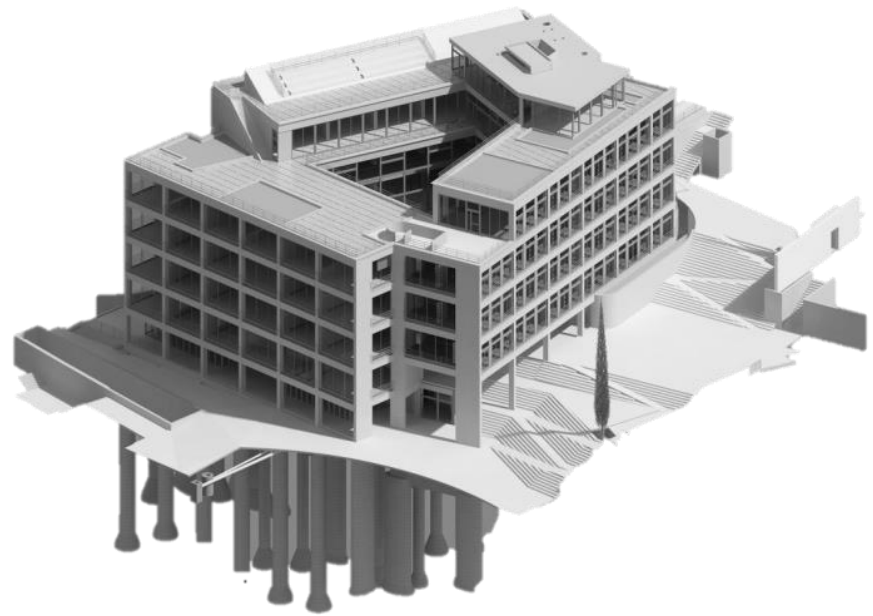

Figure 2: Revit model of Case Study

\section{TRADITIONAL METHOD RESULTS}

The structural contractor on a project was selected by a traditional method, according to the law 80 of 1993, as is shown in Figure 3 taking into account the technical and economic criteria contained in the specifications. 


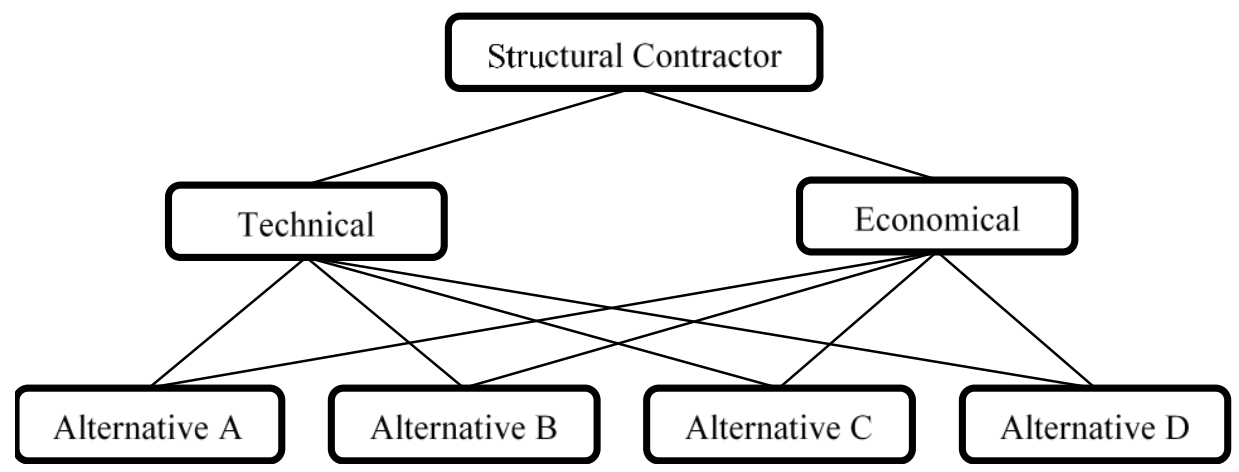

Figure 3: Multicriteria decision-analysis diagram

The economic evaluation has 700 points and the technical only 300 points. The cost as a factor has 550 of 1000 possible points (view Table 1), which tilt the balance in the cheapest alternative.

As can be seen in Table 1, the tendering $\mathrm{D}$ was the most favourable bid, and consequently, it was selected to build the structure phase of the project. Note that in the technical evaluation, it was "the worst" but due to the economic ponderation evaluation it was selected as the "the best", with a final difference of only one point.

Table 1: Results obtained by the traditional method

\begin{tabular}{|c|c|c|}
\hline \multicolumn{2}{|c|}{ Evaluation criteria } & \multirow{2}{*}{$\begin{array}{c}\text { Points } \\
150\end{array}$} \\
\hline \multirow{5}{*}{ Technical evaluation } & Business organization & \\
\hline & Management system & 50 \\
\hline & Planning and logistic & 50 \\
\hline & Makespan & 50 \\
\hline & Sub Total & Max 300 \\
\hline \multirow{9}{*}{ Economic evaluation } & Equity & 26 \\
\hline & Liquidity & 13 \\
\hline & Level of debt & 11 \\
\hline & Payment method & 25 \\
\hline & Total Cost & 550 \\
\hline & Risk management & 50 \\
\hline & Evaluation of AIU & 25 \\
\hline & Sub Total & Max 700 \\
\hline & Total & Max 1000 \\
\hline
\end{tabular}

\begin{tabular}{cccc}
\hline \multicolumn{4}{c}{ Tendering } \\
\hline $\mathbf{A}$ & $\mathbf{B}$ & $\mathbf{C}$ & $\mathbf{D}$ \\
\hline 140 & 123 & 121 & 88 \\
\hline 0 & 50 & 50 & 0 \\
\hline 50 & 48 & 50 & 38 \\
\hline 38 & 42 & 50 & 42 \\
\hline $\mathbf{2 4 0}$ & $\mathbf{2 7 2}$ & $\mathbf{2 5 5}$ & $\mathbf{2 0 9}$ \\
\hline 23 & 18 & 23 & 16 \\
\hline 13 & 13 & 13 & 13 \\
\hline 6 & 6 & 9 & 6 \\
\hline 25 & 25 & 25 & 25 \\
\hline 393 & 448 & 486 & 550 \\
\hline 50 & 45 & 45 & 40 \\
\hline 12 & 25 & 25 & 25 \\
\hline $\mathbf{5 2 6}$ & $\mathbf{5 7 4}$ & $\mathbf{6 3 3}$ & $\mathbf{6 8 0}$ \\
\hline $\mathbf{7 6 7}$ & $\mathbf{8 4 6}$ & $\mathbf{8 8 8}$ & $\mathbf{8 8 9}$ \\
\hline
\end{tabular}

\section{CBA RESULTS}

In order to validate the decision taken, it was applied the CBA method with the same criteria and using the information provided by the project manager by applying the seven steps proposed by Paz Arroyo et al. (2013). The first six steps organized in the tabular method (Table 2) and Figure 4 shows the seven-step, in which the Importance of 
Juan Pablo Romero Cortes, Jose Luis Ponz-Tienda, Jose Miguel Delgado

and Laura Gutierrez-Bucheli

Advantage (IofA) vs. cost of the alternatives is analysed. An application developed in VBA for Excel® can be downloaded from http://bit.ly/CBA_Excel.

The $\mathrm{D}$ alternative is the less favourable instead the result obtained by applying the traditional method. In Figure 4 can be seen that alternative D have a difference of almost 700 million of COP compared to the alternative $\mathrm{C}$ with, considered "the best" by CBA with more IofA.

Table 2: CBA results for steps one to six and the four alternatives (A to D).

\begin{tabular}{|c|c|c|c|c|c|c|c|c|}
\hline & \multicolumn{2}{|l|}{ A } & \multicolumn{2}{|l|}{ B } & \multicolumn{2}{|l|}{ C } & \multicolumn{2}{|l|}{ D } \\
\hline Years in construction & \multicolumn{2}{|l|}{40 years } & \multicolumn{2}{|l|}{20 years } & \multicolumn{2}{|l|}{8 years } & \multicolumn{2}{|l|}{6 years } \\
\hline More is better & 34 more years & 12 & 14 more years & 6 & 2 more years & 3 & & \\
\hline Similar experience & \multicolumn{2}{|l|}{$155,69 \mathrm{~m} 2$} & \multicolumn{2}{|l|}{$202,65 \mathrm{~m} 2$} & \multicolumn{2}{|l|}{$202,02 \mathrm{~m} 2$} & \multicolumn{2}{|l|}{$21,77 \mathrm{~m} 2$} \\
\hline More is better & $133,92 \mathrm{~m} 2$ more & 25 & $180,88 \mathrm{~m} 2$ more & 30 & $180,25 \mathrm{~m} 2$ more & 30 & & \\
\hline Bussines organization & \multicolumn{2}{|c|}{30 Professionals } & \multicolumn{2}{|l|}{40 Professionals } & \multicolumn{2}{|c|}{57 Professionals } & \multicolumn{2}{|c|}{15 Professionals } \\
\hline More is better & 15 Prof. more & 20 & 25 Prof. more & 25 & 42 Prof. more & 30 & & \\
\hline Own equipment & \multicolumn{2}{|c|}{$\$ 15,866,544.08$} & \multicolumn{2}{|l|}{$\$ 4,021,164.85$} & \multicolumn{2}{|l|}{$\$ 4,917,604.93$} & \multicolumn{2}{|c|}{$\$ 1,029,660.96$} \\
\hline More is better & $\$ 14,836,883.12$ & 30 & $\$ 2,991,503.89$ & 10 & $\$ 3,887,943.97$ & 10 & & \\
\hline ISO Certifications & \multicolumn{2}{|l|}{ SIG } & \multicolumn{2}{|c|}{ 9001-18001-14001 } & \multicolumn{2}{|l|}{9001} & \multicolumn{2}{|l|}{ SIG } \\
\hline At least one (1) & & & Have 3 certification & $\mathbf{5 0}$ & Have at least one & 50 & & \\
\hline Makespan & \multicolumn{2}{|l|}{14,5 months } & \multicolumn{2}{|l|}{13 month } & \multicolumn{2}{|l|}{11 month } & \multicolumn{2}{|l|}{13 month } \\
\hline Less is better & & & 1,5 month less & 40 & 3,5 month less & $\mathbf{5 0}$ & 1,5 month less & 40 \\
\hline Equity & \multicolumn{2}{|l|}{$22,55 \mathrm{smmlv}$} & \multicolumn{2}{|l|}{$8,21 \mathrm{smmlv}$} & \multicolumn{2}{|l|}{$33,33 \mathrm{smmlv}$} & \multicolumn{2}{|l|}{$2,54 \mathrm{smmlv}$} \\
\hline More is better & 20,01 smmlv (2) & 18 & $5,67 \mathrm{smmlv}$ & 10 & $30,79 \mathrm{smmlv}$ & 26 & & \\
\hline Liquidity & 2,18 & & 3,2 & & 4,47 & & 2,5 & \\
\hline More is better & & & 1,02 more & 7 & 2,29 more & 13 & 0,32 more & 4 \\
\hline Level of debt & 63,3 & & 28,75 & & 30,76 & & 31,48 & \\
\hline Less is better & & & 34,6 less & 11 & 32,54 less & 11 & 31,82 less & 11 \\
\hline Payment method & 0,3 & & 0,3 & & 0,3 & & 0,3 & \\
\hline Less is better & & & & & & & & \\
\hline Risk management & $\$ 26,943,619.5$ & & $\$ 8,554,684.62$ & & $\$ 20,564,512.9$ & & $\$ 2,040,078$. & \\
\hline More is better & $\$ 24,903,540.67$ & 50 & $\$ 6,514,605.72$ & 15 & $\$ 18,524,434.09$ & 30 & & \\
\hline Evaluation of AIU & 0,41 & & 0,48 & & 0,33 & & 0,23 & \\
\hline Less is better & 0,07 & 10 & & & 0,15 & 15 & 0,25 & 25 \\
\hline TOTAL IofA & 165 & & 204 & & 268 & & 80 & \\
\hline
\end{tabular}

Notes: (1) At least one of of ISO 9001-18001-14001

(2) smmlv is the spanish acronym of current legal minimum monthly salary 


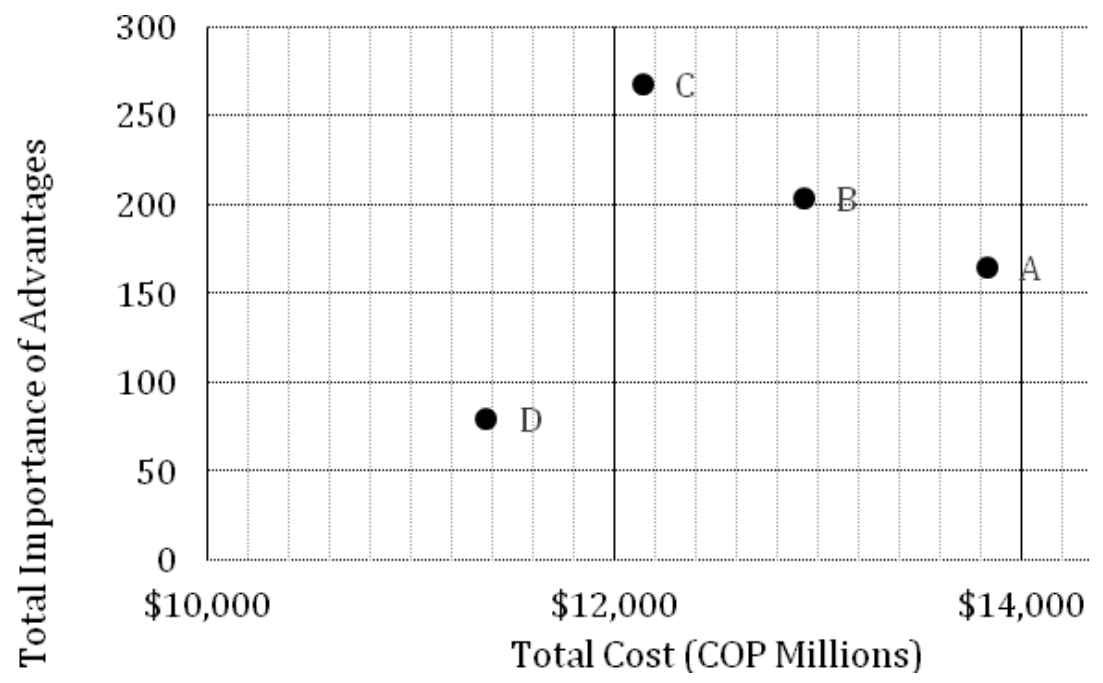

Figure 4: CBA results IofA vs. Total cost

\section{DISCUSSION OF THE RESULTS}

This comparison allows analysing the decision in two different perspectives of the construction management: the management in the world of the cost and the management in the world of the value. These differences are reflected in the results shown in Figure 5.

The obtained results were in line with the expected: the best option applying the traditional method is the worst by applying CBA. In the CBA method, the differences among alternatives $\mathrm{A}$ and $\mathrm{B}$ decreases, while the alternatives $\mathrm{C}$ and $\mathrm{D}$ change in the order of preference. Additionally, the difference between $\mathrm{C}$ and $\mathrm{D}$, increase from 1 point to 188 points or IofA showing that $\mathrm{CBA}$ considers that the best alternative is the one that provides more value to the project.

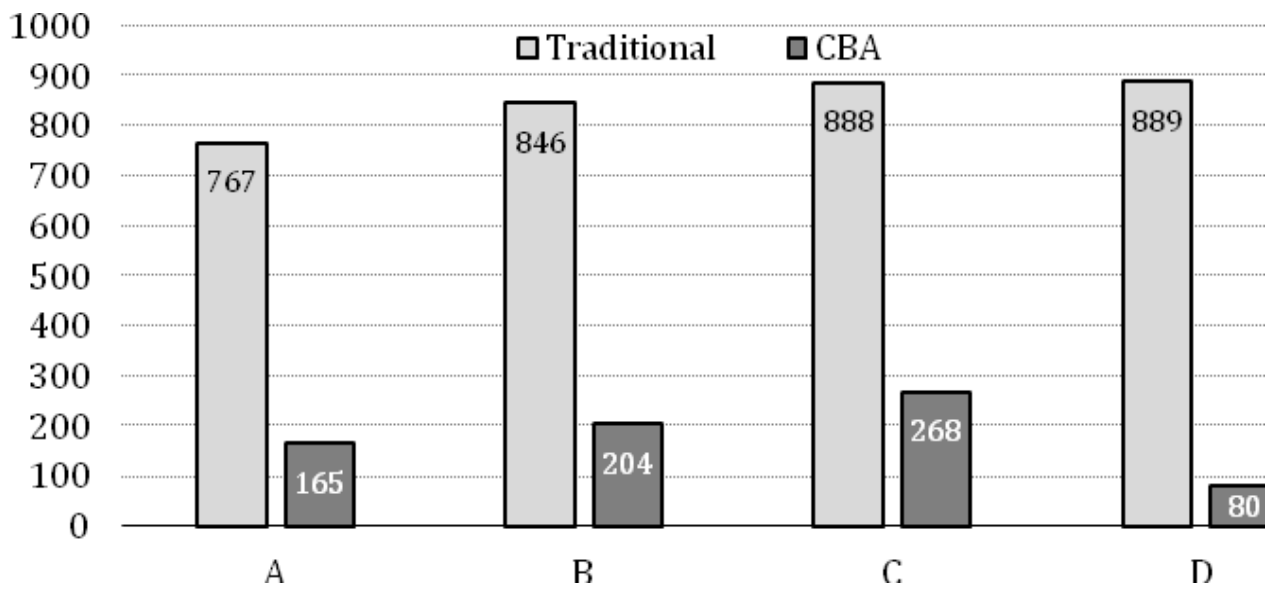

Figure 5: Comparison of results Traditional vs. CBA

Nevertheless, it is important to highlight that the alternative $\mathrm{D}$, selected by the traditional method, only obtain advantage in a few factors by applying the CBA method, 
Juan Pablo Romero Cortes, Jose Luis Ponz-Tienda, Jose Miguel Delgado

and Laura Gutierrez-Bucheli

being the worst ranked in: a) construction experience (in years), b) experience in similar buildings, c) business organization, d) own equipment, e) ISO certifications, f) equity, g) payment method, and h) risk management. This could be the reason why the problems arose and the project manager wondered if it was the right decision. The analysis of the results shows the benefits of $\mathrm{CBA}$ as an effective decision making tool compared to the traditional methods.

\section{CONCLUSIONS AND LIMITATIONS}

The present research has analysed and compared the traditional method applied in Colombia for the selection and hiring of services provider with the CBA method in the process of select the structural contractor for an academic building in order to validate the decision made by the traditional method.

Therefore, the difference of the results among alternatives varies among methods; partly, as a consequence of not considering the cost as the main criterion. In addition, in CBA, the results of alternatives are easy to analyse, identifying the advantages, the factors in which is the difference and offer clearness to the criteria. Also, the traditional way in which decisions are taken is targeted on the result, disparaging the methodology to obtain it. Nevertheless, the making decision method is also important as the alternative selected.

Finally, it is considered that this case study does not evaluate if the factors were the correct and if the criteria was the right one; as a result, this is material for another research because it is not enough to use a different method of selection, it is also required to know how to use it. In this case, it implies to define correctly the factors, criteria and importance of each advantage.

\section{ACKNOWLEDGEMENTS}

The authors would like to acknowledge the faith and support provided by the staff of the Campus manage from Los Andes University and all the research assistants of INGeCo (Research Group in Engineering and Construction Management) of the Universidad de Los Andes.

\section{REFERENCES}

Abraham, K., Lepech, M., and Haymaker, J. (2013). "Selection and application of choosing by advantages on a corporate campus project." Proc. of 21st Ann. Conf. of Int'l Group for Lean Construction. Fortaleza, Brazil

Arroyo, P., Tommelein, I. D., and Ballard, G. (2012). "Deciding a sustainable alternative by "Choosing by advantages" in the AEC industry." Proc. of 20th Ann. Conf. of Int'l Group for Lean Construction. San Diego, CA, USA

Arroyo, P., Tommelein, I. D., and Ballard, G. (2013). "Using " Choosing by advantages" to select ceiling tile from a global sustainable perspective." Proc. of 21st Ann. Conf. of Int'l Group for Lean Construction. Fortaleza, Brazil 
Arroyo, P., Tommelein, I. D., and Ballard, G. (2016). "Selecting Globally Sustainable Materials: A Case Study Using Choosing by Advantages." J. Constr. Eng. Manage., 142(2), 10.1061/(ASCE)CO.1943-7862.0001041

Cheng, E. W. L., and Li, H. (2004). "Contractor selection using the analytic network process." Construction Management and Economics, 22(10), 1021-1032. DOI: 10.1080/0144619042000202852

Fallah-Mehdipour, E., Bozorg Haddad, O., Rezapour Tabari, M. M., and Mariño, M. A. (2012). "Extraction of decision alternatives in construction management projects: Application and adaptation of NSGA-II and MOPSO." Expert Systems with Applications, 39(3), 2794-2803. DOI: 10.1016/J.ESWA.2011.08.139

Holt, G. D., Olomolaiye, P. O., and Harris, F. C. (1995). "A review of contractor selection practice in the U.K. construction industry." Building and Environment, 30(4), 553-561. DOI: 10.1016/0360-1323(95)00008-T

Karakhan, A., Gambatese, J., and Rajendran, S. (2016). "Application of choosing by advantages decision-making system to select fall-protection measures." Proc. of the 24th Ann. Conf. of the Int'l Group for Lean Construction. Boston, MA, USA

Kpamma, Z. E., Adinyira, E., Ayarkwa, J., and Adjei-Kumi, T. (2016). "Application of the CBA Decision System to Manage User Preferences in the Design Process." J. Prof. Issues Eng. Educ. Pract., 142(1), DOI: 10.1061/(ASCE)EI.1943-5541.0000258

Kumar, A., Sah, B., Singh, A. R., Deng, Y., He, X., Kumar, P., and Bansal, R. C. (2017). "A review of multi criteria decision making (MCDM) towards sustainable renewable energy development." Renewable and Sustainable Energy Reviews, 69, 596-609. DOI: 10.1016/J.RSER.2016.11.191

Martinez, E., Tommelein, I. D., and Alvear, A. (2016). "Formwork System Selection Using Choosing by Advantages." Construction Research Congress 2016, SanJuan, Puerto Rico, 1700-1709.

Mejía-Plata, C., Guevara-Ramirez, J. S., Moncaleano-Novoa, D. F., Londoño-Acevedo, M. C., Rojas-Quintero, J. S., and Ponz-Tienda, J. L. (2016). "A Route Map for Implementing Last Planner® System in Bogotá, Colombia." Proc. of the 24th Ann. Conf. of the Int'l Group for Lean Construction. Boston, MA, USA

Opricovic, S., and Tzeng, G.-H. (2004). "Compromise solution by MCDM methods: A comparative analysis of VIKOR and TOPSIS." European Journal of Operational Research, 156(2), 445-455. DOI: 10.1016/S0377-2217(03)00020-1

Parrish, K., and Tommelein, I. D. (2009). "Making design decisions using choosing by advantages." Proc. of the 17th Ann. Conf. of the Int'l Group for Lean Construction. Taipei, Taiwan

Pellicer, E., and Ponz-Tienda, J. L. (2014). "Teaching and Learning Lean Construction in Spain: A pioneer Experience. In B. T. Kalsaas, L. Koskela, \& T. A. Saurin (Eds.)", Proc. of the 22nd Ann. Conf. of the Int'l Group for Lean Construction. Oslo, Norway 
Juan Pablo Romero Cortes, Jose Luis Ponz-Tienda, Jose Miguel Delgado and Laura Gutierrez-Bucheli

Schöttle, A., \& Arroyo, P. (2017)." Comparison of Weighting-Rating-Calculating, Best Value, and Choosing by Advantages for Bidder Selection." J. Constr. Eng. Manage., 143(8), 10.1061/(ASCE)CO.1943-7862.0001342

Suhr, J. (1999). The choosing by advantages decisionmaking system. (Quorum Books, Ed.). Westport, Connecticut.

Vallejo-Borda, J. A., Gutierrez-Bucheli, L. A., Pellicer, E., and Ponz-Tienda, J. L. (2015). "Application of AHP for the Criteria Evaluation of a Public Procurement in Colombia." International Journal of Civil and Structural Engineering, 2(2), 87-94. DOI: $10.15224 / 978-1-63248-062-0-67$ 